\title{
Controlling Hydrocarbon (De)Hydrogenation Pathways with Bifunctional PtCu Single-Atom Alloys
}

\author{
Romain Réocreux, ${ }^{\text {a }}$ Paul L. Kress, ${ }^{b}$ Ryan T. Hannagan, ${ }^{b}$ Volkan Çınar, ${ }^{b}$ Michail \\ Stamatakis, $^{\text {a* }}$ E. Charles H. Sykes ${ }^{\mathrm{b} *}$ \\ a Thomas Young Centre and Department of Chemical Engineering, University College London, \\ Roberts Building, Torrington Place, London WC1E 7JE, United Kingdom \\ b Department of Chemistry, Tufts University, 62 Talbot Ave., Medford, Massachusetts 02155 , \\ United States \\ $\$$ these authors contributed equally to this manuscript
}

\begin{abstract}
:
The conversion of surface-bound alkyl groups to alkanes and alkenes are important steps in many heterogeneously catalyzed reactions. While Pt is ubiquitous in industry because of its high activity toward $\mathrm{C}-\mathrm{H}$ activation, many $\mathrm{Pt}$ based catalysts tend to over-bind reactive intermediates, which leads to deactivation by carbon deposition and coke formation. On the other hand, Cu binds intermediates more weakly than Pt but activation barriers tend to be higher on $\mathrm{Cu}$. We examine the reactivity of ethyl, the simplest alkyl group that can undergo hydrogenation and dehydrogenation via $\beta$-elimination, and show that isolated $\mathrm{Pt}$ atoms in $\mathrm{Cu}$ enable low temperature hydrogenation of ethyl, unseen on $\mathrm{Cu}$, while avoiding the decomposition pathways on pure Pt that lead to coking. Furthermore, we confirm the predictions of our theoretical model and experimentally demonstrate that the selectivity of ethyl (de)hydrogenation can be controlled by changing the surface coverage of hydrogen.
\end{abstract}

Table of Content Graphics $(5 \mathrm{~cm} \times 5 \mathrm{~cm})$
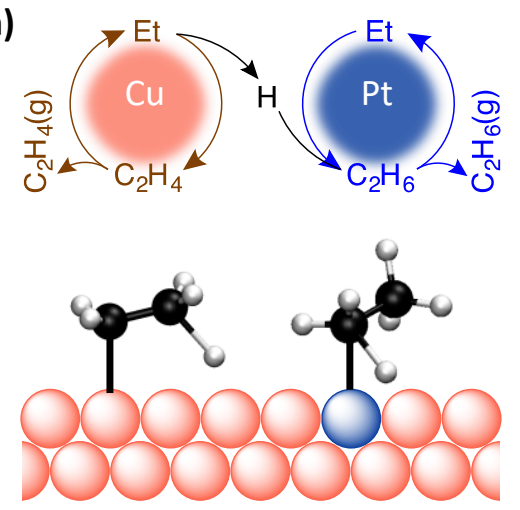

Keywords: Single-atom alloys, hydrogenation, dehydrogenation, bifunctional, heterogenous catalysis 
Single-atom alloys (SAAs) are an emerging class of heterogeneous catalysts in which a small amount of a more reactive dopant metal is atomically dispersed in the surface layer of a less reactive host metal. ${ }^{1-3}$ Due to their ability to perform a range of efficient and selective chemistries, there has been growing interest in this class of single-site catalysts in recent years. ${ }^{4-10}$ Specifically SAAs have been demonstrated to efficiently catalyze hydrogenation, ${ }^{9,11} \mathrm{C}-\mathrm{C}$ coupling, ${ }^{12,13}$ NO reduction, ${ }^{14}$ oxygen reduction, ${ }^{15} \mathrm{CO}_{2}$ reduction ${ }^{16,17}$ and coke-free $\mathrm{C}-\mathrm{H}$ activation ${ }^{18,19}$ among many other reactions. ${ }^{1,20}$ Due to the well-defined nature of their active sites and the possibility for intermediates to spill over from dopant to host, these SAAs can break traditional linear scaling relationships that limit catalytic performance. ${ }^{1,6,21,22}$ Furthermore, the weaker binding of most species to SAA surfaces vs. traditional catalytic metals like Pt, Pd and Ni offers solutions to common problems that plague these catalysts like $\mathrm{CO}$ poisoning and coking by carbonaceous species. Coking is of particular interest in the industrial hydrogenation and dehydrogenation of organic compounds (such as hydrocarbons and oxygenates), as strong binding of carbonaceous species leads to catalyst deactivation.

Surface bound alkyl groups are ubiquitous in many reaction pathways and the relative ease of their hydrogenation/dehydrogenation is critical to product selectivity. ${ }^{23}$ Ethyl groups are prototypical intermediates that can be hydrogenated to ethane, dehydrogenated to ethylene via $\beta$-hydride elimination, or decomposed to $\mathrm{CH}_{\mathrm{x}}$ fragments on the surface. $\beta$-hydride elimination is the most facile dehydrogenation step on most metal surfaces. ${ }^{23-25}$ Therefore, driving a catalytic process involving alkyl groups towards the desired products (alkanes, olefins) is non-trivial and, as we show here, SAAs may be key to achieving greater control over the product selectivity. Herein, we take a surface science and theory approach to understanding and quantifying the energetics of these relevant reaction pathways on PtCu SAAs. Relevant to the present work, the hydrogenation and dehydrogenation of ethyl groups have been studied on both $\mathrm{Cu}$ and Pt surfaces. On $\mathrm{Cu}(111)$, ethyl only undergoes a $\beta$-elimination to yield hydrogen and ethylene, which desorbs at $247 \mathrm{~K}^{26}$ Studies show that while $\mathrm{Cu}(111)$ can enable H/D exchange reactions in adsorbed ethyl, it is incapable of hydrogenating ethyl groups to ethane. ${ }^{27}$ This suggests the existence of a surface-bound ethyl group that will not fully hydrogenate to ethane, consistent with a DFT investigation by $\mathrm{Xu}$ et al. ${ }^{28}$ showing that ethylene would rather desorb from copper than hydrogenate to ethane. In contrast, on $\mathrm{Pt}(111)$ the picture is much more complex. There is experimental and theoretical evidence of a large dehydrogenation reaction network that leads to various $\mathrm{C}_{2} \mathrm{H}_{x}$ surface-bound intermediates such as vinyl $\left(\mathrm{CH}_{2} \mathrm{CH}\right)$, vinylidene $\left(\mathrm{CH}_{2} \mathrm{C}\right)$, and particularly stable ethylidyne $\left(\mathrm{CH}_{3} \mathrm{C}\right) .{ }^{29-31}$ Dehydrogenation steps via both $\alpha$ - and $\beta$-hydride elimination are particularly active on Pt. These unsaturated intermediates ultimately undergo C-C cleavage and 
decompose to coke at high temperatures, producing large amounts of adsorbed hydrogen, which can either desorb as $\mathrm{H}_{2}$ or hydrogenate $\mathrm{C}_{1}$ and $\mathrm{C}_{2}$ species to methane and ethane respectively. The carbon left behind on the Pt surface poisons the active sites, which is a common problem for hydrocarbon conversion on Pt catalysts. ${ }^{32-34}$ For the selective interconversion of $\mathrm{C}-\mathrm{C}$ and $\mathrm{C}=\mathrm{C}$ bonds, the ideal catalyst should be able to hydrogenate unsaturated adsorbates (like Pt can do), and conversely, dehydrogenate alkyl groups to alkenes (like $\mathrm{Cu}$ and Pt) but without deactivation due to coking seen for pure Pt. PtCu alloys appear promising for this reaction, and in particular PtCu SAAs which are known to enable facile $\mathrm{C}-\mathrm{H}$ activation and are coke resistant. ${ }^{19}$ To gain insight into the reactivity and degree of bifunctionality of such alloys, we combined theory and experiments to understand the disproportionation of a model adsorbate, namely ethyl, to ethane and ethylene on PtCu alloys. Results from our theoretical model enabled us to experimentally demonstrate that the selectivity of ethyl (de)hydrogenation can be controlled by adjusting the surface coverage of hydrogen.
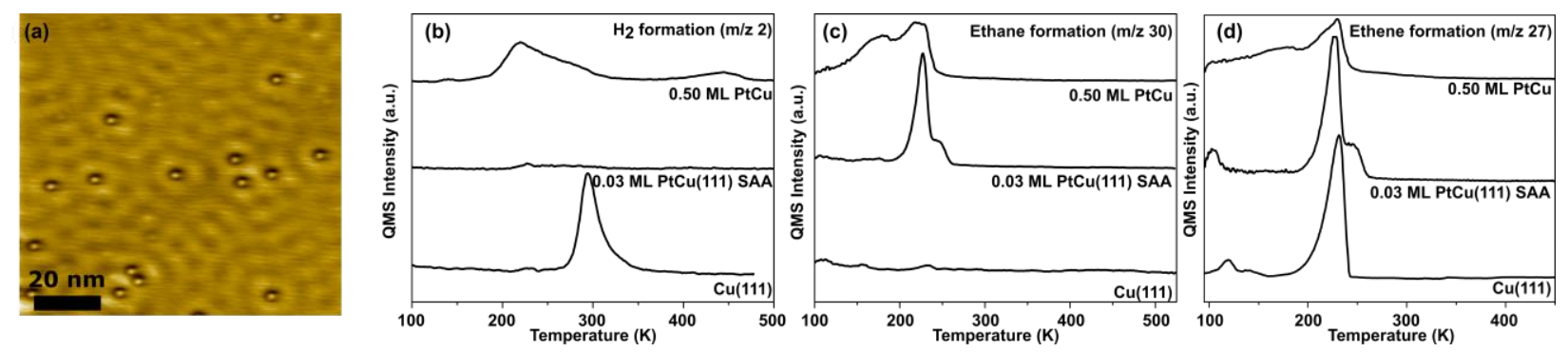

Figure 1. (a) STM image of PtCu(111) SAA. (b) TPD traces for hydrogen desorption from $\mathrm{Cu}(111), 0.03 \mathrm{ML}$ PtCu SAA and 0.50 ML PtCu respectively after deposition of $6 \mathrm{~L}$ of ethyl iodide. (c) Ethane and (d) ethylene formation from the same three experiments showing that Pt is necessary for the hydrogenation of ethyl groups to ethane.

In order to probe $\beta$-hydride elimination reactivity which is central to the interconversion of molecules with $\mathrm{C}=\mathrm{C}$ and $\mathrm{C}-\mathrm{C}$ bonds, we performed Temperature Programmed Desorption (TPD) experiments to investigate the reaction pathways of ethyl groups generated in situ from ethyl iodide on $\mathrm{PtCu}$ alloys with different surface compositions. Ethyl iodide is known to react on $\mathrm{Cu}$ at low temperature ( $140 \mathrm{~K})$ to produce adsorbed Et groups and I atoms. ${ }^{35}$ When a saturation dose of ethyl iodide $(6 \mathrm{~L})$ is deposited on pure $\mathrm{Cu}(111)$, TPD experiments reveal that ethylene desorbs at $230 \mathrm{~K}$ and hydrogen at 300 $\mathrm{K}$ (Figure $1 \mathrm{~d}$ and $\mathrm{b}$ ), with no desorption of ethane (Figure 1c). The surface-bound hydrogen atoms resulting from the $\beta$-hydride elimination of surface-bound ethyl groups therefore act as spectators that do not participate to the production of ethane. In contrast, when the same experiments are carried out on 0.5 monolayer (ML) PtCu surface alloys, ethane is produced and desorbs at 150-250 K (Figure 1c), followed by the desorption of $\mathrm{H}_{2}$ between 200-300 K (Figure 1b). Furthermore, the TPD spectra exhibit a 
second $\mathrm{H}_{2}$ desorption feature at higher temperature ( $\left.\sim 450 \mathrm{~K}\right)$. Related to this, it is known that reaction of ethyl groups on pure Pt surfaces leads to very similar TPD spectra, ${ }^{24}$ indicating that our $0.5 \mathrm{ML}$ Pt surface alloys consist of extended Pt-islands with a reactivity comparable to that of pure Pt. C-H activation can occur at a low temperature on Pt, producing hydrogen that can either hydrogenate surface-bound ethyl groups or associatively desorb as $\mathrm{H}_{2}{ }^{24,36}$ The second $\mathrm{H}_{2}$ desorption peak at higher temperature results from further decomposition. ${ }^{36}$ The complexity of the TPD traces from our $0.5 \mathrm{ML}$ $\mathrm{PtCu}(111)$ alloys is representative of the many reaction pathways that occur on extended Pt surfaces. ${ }^{36}$

Moving to the single-atom limit, for $0.03 \mathrm{ML} \mathrm{PtCu(111)} \mathrm{SAA} \mathrm{surfaces,} \mathrm{we} \mathrm{find} \mathrm{that} \mathrm{ethyl} \mathrm{groups}$ react to produce ethane and ethylene at $230 \mathrm{~K}$ as seen in Figure $1 \mathrm{c}$ and $\mathrm{d}$, but no $\mathrm{H}_{2}$ is produced, contrary to the behavior of pure $\mathrm{Cu}$, pure $\mathrm{Pt}^{37}$ and $0.5 \mathrm{ML} \mathrm{PtCu}$. Scanning Tunneling microscopy (STM) imaging reveals that the $0.03 \mathrm{MLPtCu}(111)$ alloy is indeed a SAA, as the surface Pt atoms are atomically dispersed in the surface of $\mathrm{Cu}$ (Figure 1a), in agreement with previous experimental and theoretical studies. ${ }^{38-41}$ Previous DFT calculations ${ }^{40}$ have showed that both segregation (migration of Pt to bulk $\mathrm{Cu}$ ) and aggregation (formation of surface clusters) are endothermic ( $0.15 \mathrm{eV}$ and $0.09 \mathrm{eV}$ respectively), thereby explaining the stability of the SAA phase. The hydrogenation of ethyl to ethane, which is not possible on pure $\mathrm{Cu}$, is therefore catalyzed by individual, isolated $\mathrm{Pt}$ atoms in the surface layer of $\mathrm{Cu}(111)$. By comparing to our 0.5 ML PtCu data, we see that reducing the Pt site ensembles down to single-atoms prevents the adsorbates from fully dehydrogenating and decomposing to yield high temperature $\mathrm{H}_{2}$. We have previously studied a range of surface coverages of $\mathrm{Pt}$ on/in $\mathrm{Cu}(111)$ under the same alloying conditions and these STM results revealed that deposition of $0.5 \mathrm{ML}$ Pt on $\mathrm{Cu}(111)$ leads to the growth of extended $\mathrm{Pt}(111)$ like islands on the $\mathrm{Cu}$ surface. ${ }^{42}$ This indicates that the PtCu SAA is a bifunctional surface on which $\mathrm{Cu}$ performs the dehydrogenation step while the Pt sites facilitate the hydrogenation without decomposition. Our DFT results (see Scheme S1) support this hypothesis, and are in line with previously reported studies. ${ }^{43,44}$ Briefly, while $\mathrm{Pt}(111)$ stabilizes most $\mathrm{C}_{2} \mathrm{H}_{\mathrm{x}}(2 \leq x \leq 6)$ species on the surface (with ethylidyne $\mathrm{CH}_{3} \mathrm{C}$ being the most stable), $\mathrm{PtCu}(111)$ SAAs only stabilize ethane, ethyl and $\pi$-bonded ${ }^{45}$ ethylene, greatly simplifying the reaction network found on $\mathrm{Pt}(111)$ and thereby only enabling desired $\mathrm{C}=\mathrm{C} / \mathrm{C}-\mathrm{C}$ interconversion steps. 
(a) Reactivity on $\mathrm{Cu}(111)$
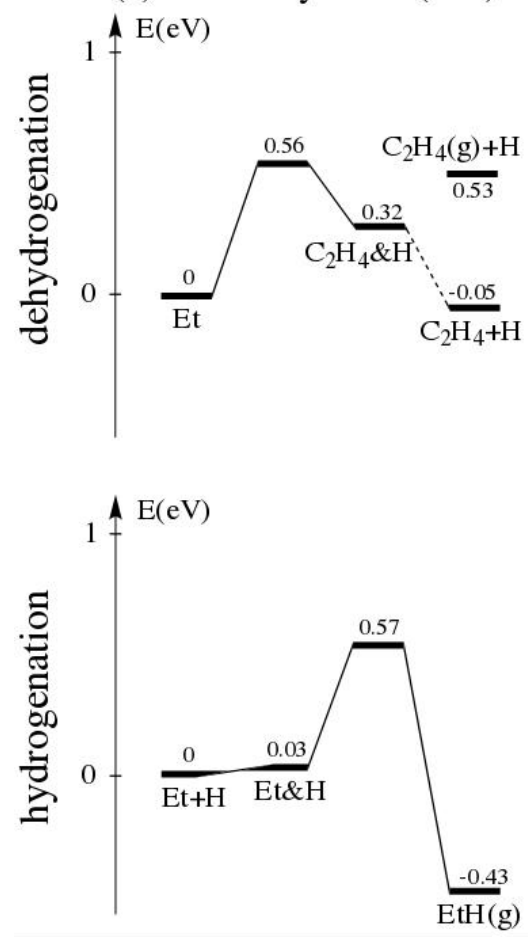

(b) Structures of the transition states
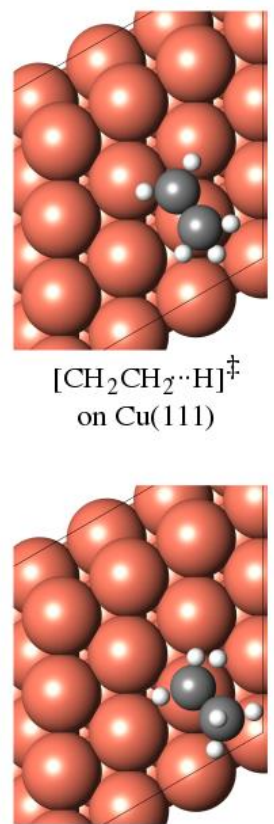

$\left[\mathrm{H}^{\cdots} \mathrm{CH}_{2} \mathrm{CH}_{3}\right]^{\dagger}$ on $\mathrm{Cu}(111)$
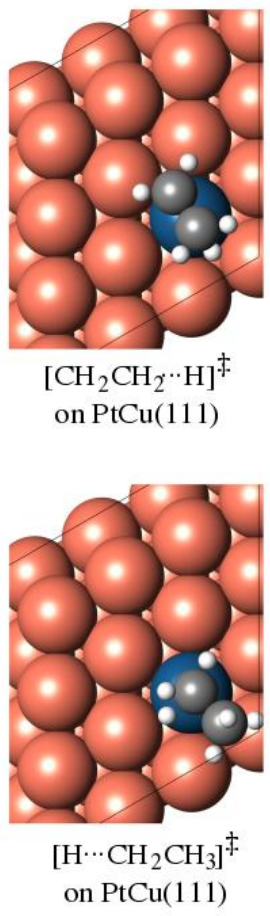

(c) Reactivity on $\mathrm{PtCu}(111)$ SAA
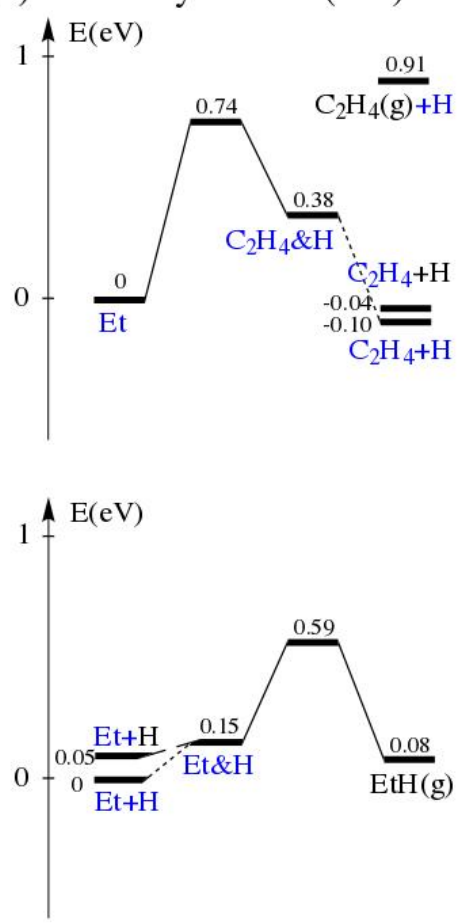

Figure 2. DFT-proposed mechanism for the hydrogenation and dehydrogenation of surface-bound ethyl (Et) groups. The energetics of the different reaction steps are given for (a) $\mathrm{Cu}(111)$ and (c) PtCu(111) SAA. The structures of the transition states are given in (b). A\&B represents the co-adsorbed state of $A$ and $B$ while $A+B$ represents the state of infinite separation on the surface. Adsorbates on $\mathrm{Cu}$ and $\mathrm{PtCu}$ mixed sites are reported in black and blue respectively. All species are surface-bound unless explicitly denoted as gas species by '(g)'.

In order to more fully elucidate the product selectivity observed in experiments, we performed DFT calculations to quantify the energetics of the different reaction steps, placing particular focus on the activation energies for both the hydrogenation and dehydrogenation of ethyl groups on $\mathrm{Cu}(111)$ and PtCu(111) SAA surfaces. In Figure 2a (top panel) it can be seen that on $\mathrm{Cu}(111)$, the dehydrogenation of ethyl has an activation energy of $0.56 \mathrm{eV}$ and is almost athermic. The hydrogenation step shows a similar activation energy, $0.57 \mathrm{eV}$ (Figure $2 \mathrm{~b}$, bottom panel), which is surprising given that our experiments show that $\mathrm{Cu}$ cannot hydrogenate ethyl groups, and we will return to this point later in the paper. On the PtCu(111) SAA surface, the similar stabilization of both ethyl and ethylene on the Pt site $(-0.42 \mathrm{eV}$ for both adsorbates compared to $\mathrm{Cu}$ sites, see Table S1) keeps the dehydrogenation step athermic. Interestingly, the transition state on the SAA does not show the same extent of stabilization as the initial and final states (only $-0.25 \mathrm{eV}$, see Table S1) leading to a barrier of $0.74 \mathrm{eV}$, and this is in spite of the very similar geometries on both surfaces (Figure 2b). Pt sites are therefore unlikely to compete with $\mathrm{Cu}$ sites in the ethyl dehydrogenation step. However, the Pt single atom sites open a hydrogenation pathway 
with an overall activation energy of $0.54-0.59 \mathrm{eV}$ (depending on whether hydrogen is adsorbed on either Cu or Pt sites).

Crucially, the activation energy just noted is very similar to that of the hydrogenation on $\mathrm{Cu}$ $(0.57 \mathrm{eV})$, which might seem at odds with the experimental data, as this process is not observed on pure $\mathrm{Cu}$ by either ourselves or others. ${ }^{46}$ One might argue that since ethyl and hydrogen bind more strongly on Pt, the latter site would be responsible for the hydrogenation. However, this could be counteracted by the (much) larger population of $\mathrm{Cu}$ sites relative to $\mathrm{Pt}$. It is also interesting that even though hydrogenation and dehydrogenation have similar barriers on $\mathrm{Cu}$, only the latter is observed experimentally. This could be attributed to the different reaction orders: the second-order hydrogenation step might not be able to compete with the first-order dehydrogenation step on $\mathrm{Cu}$, unless hydrogen is present at sufficiently high surface coverages. 

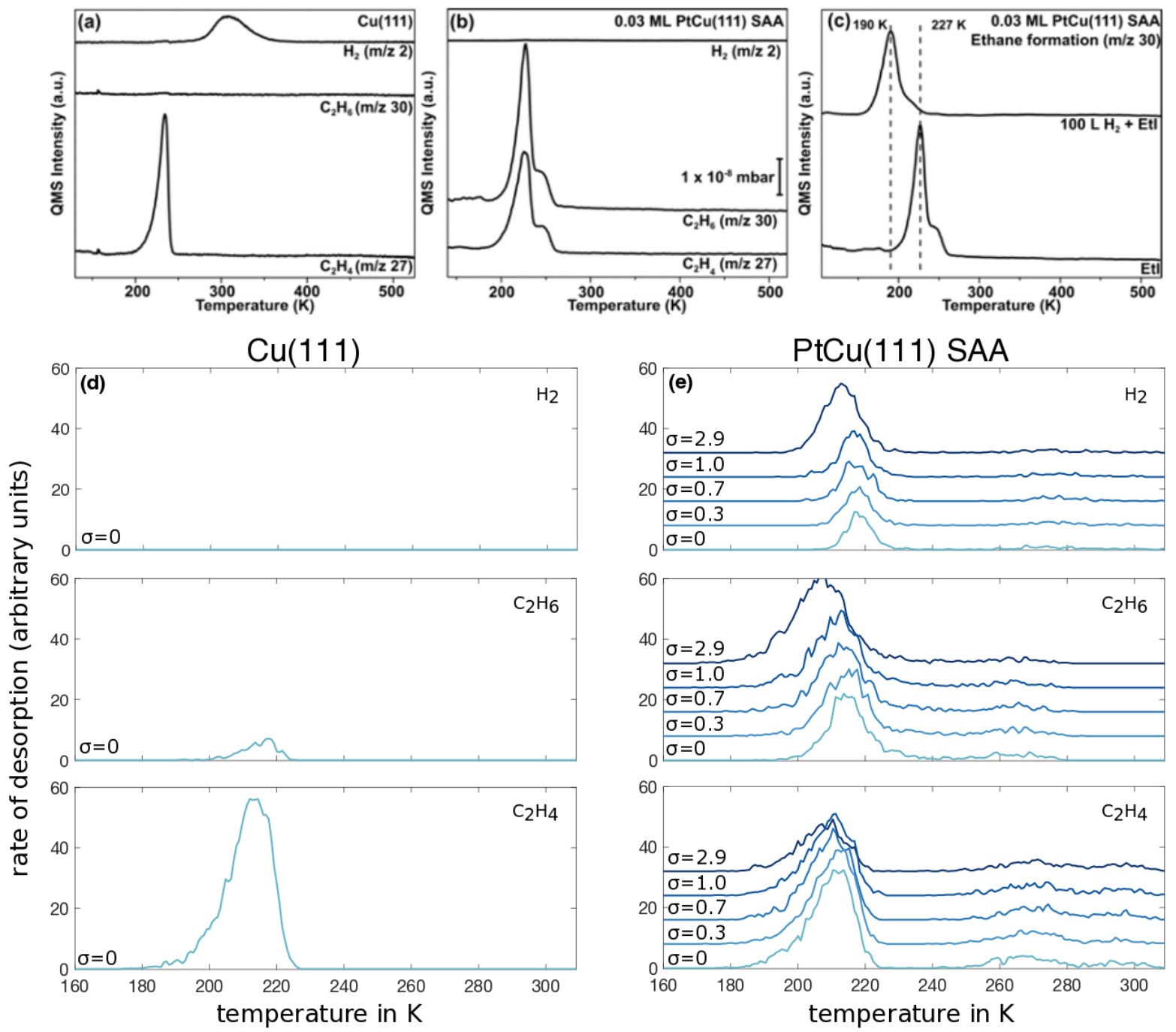

Figure 3. Experimental (a-c) and simulated (d-e) TPD spectra (hydrogen, ethane and ethylene) revealing the reactivity of ethyl groups on different surfaces. Experimental TPD Traces (after saturation with 6 L ethyl iodide exposure) on (a) pure $\mathrm{Cu}(111)$, (b) $0.03 \mathrm{ML} \mathrm{PtCu}(111) \mathrm{SAA}$, (c) $0.03 \mathrm{ML} \mathrm{PtCu}(111)$ SAA pre-covered with hydrogen. Simulated TPD spectra on (d) pure $\mathrm{Cu}(111)$ and (e) $0.03 \mathrm{ML} \mathrm{PtCu(111)} \mathrm{SAA} \mathrm{with} \mathrm{various} \mathrm{amounts} \mathrm{of}$ pre-covered hydrogen, expressed as $\sigma=[\mathrm{H}]_{0}:[\mathrm{Pt}]$. Each simulated TPD signal is the average of $10 \mathrm{different}$ simulations for a given initial coverage of $\mathrm{H}$. The traces are shifted vertically for clarity.

To elucidate the complex interplay between these effects and identify the preferred reaction pathway(s) we adopted a kinetic modelling approach. We performed DFT-parametrized kinetic Monte Carlo (kMC) simulations that could be directly compared with TPD experiments in order to obtain a more detailed mechanistic picture of these reaction steps. Experimentally, on both $\mathrm{Cu}(111)$ and the $\mathrm{PtCu}(111) \mathrm{SAA}$, ethylene is produced at around $230 \mathrm{~K}$ (see TPD spectra in Figure 3a-b). Simulations show that ethylene indeed desorbs at the same temperature on the different surfaces (see simulated TPD 
spectra in Figure $3 \mathrm{~d}$-e). The position of the simulated desorption peak temperature ( $215 \mathrm{~K})$ agrees well with the experimental data. A detailed analysis of reaction rates in the kMC simulations (Figure S4) shows that, even on the PtCu(111) SAA, ethylene desorption is limited by $\beta$-hydride elimination on $\mathrm{Cu}$ sites, which supports our hypothesis that Pt sites are not involved in the dehydrogenation route. On pure $\mathrm{Cu}(111)$, a small fraction of ethyl $(\sim 7.1 \pm 0.2 \%)$ is hydrogenated by the endogenously produced hydrogen atoms. However, most of the hydrogen atoms remain on the surface until they reach the temperature of associative desorption (above $400 \mathrm{~K}$, see Figure S6). Importantly, almost equal amounts of ethane and ethylene are synchronously produced on $\mathrm{PtCu}(111)$ SAAs. Our kMC simulations show that the hydrogenation is more than one order of magnitude faster ( $~ 30$ times) on single atom Pt sites than on Cu sites, and now competes with the dehydrogenation pathway on Cu sites (Figure S4). This confirms the bifunctional nature of the model catalyst whereby each metal performs one elementary step of the reaction. Moreover, hydrogen reaches lower coverages on PtCu compared to pure Cu (Figure S5) due to the facile recombination of hydrogen and ethyl groups towards ethane on Pt sites. Since ethane desorbs rapidly, the net effect is hydrogen depletion from the $\mathrm{PtCu}$ surface via this pathway. Since the hydrogenation step can only occur when hydrogen atoms are produced from the competing dehydrogenation route, the kinetics are coupled. To decouple these pathways, and potentially promote the hydrogenation reaction, our simulations suggest that we would need to add hydrogen to the surface. PtCu SAAs readily activate $\mathrm{H}_{2}$ and enable $\mathrm{H}$ atom spillover to $\mathrm{Cu}(111)$, as demonstrated experimentally. ${ }^{11,42}$ Therefore, we tested our prediction experimentally by pre-dosing the SAA surface with hydrogen before running the ethyl iodide experiment. The experimental data in Figure $3 \mathrm{c}$ show that the ethane desorption peak derived from the hydrogenation step is shifted to a lower temperature, demonstrating that hydrogenation is indeed faster than dehydrogenation when not limited by the production of surface hydrogen as our modeling indicates. 

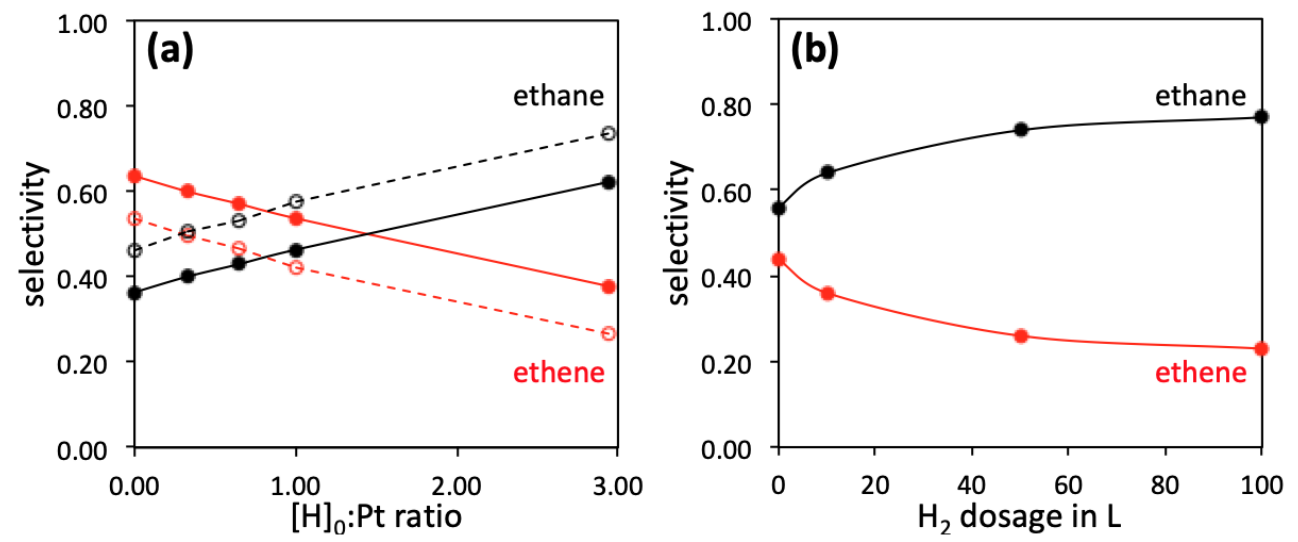

Figure 4. Effect adding surface hydrogen on the selectivity of ethyl disproportionation on 0.03 ML PtCu SAA. (a) Simulated selectivity as a function of the initial amount of $\mathrm{H}$ normalized by the number of Pt sites. The solid lines are for the full model. The dashed lines are for a model that does not allow for associative desorption of hydrogen. (b) Experimental selectivity to ethane vs. ethylene as a function of the amount of $\mathrm{H}_{2}$ deposited.

Figure 4 shows good agreement between experiment and theory for the effect of pre-depositing $\mathrm{H}_{2}$ on the surface and illustrates that by adjusting surface hydrogen coverage, the reaction selectivity can be controlled. Specifically, Figure 4 shows the simulated selectivity as a function of the initial coverage of hydrogen (Figure 4a) and the experimental selectivity as a function of the amount of $\mathrm{H}_{2}$ deposited before the reaction (Figure $4 \mathrm{~b}$ ). At low hydrogen coverages, ethane and ethylene are produced in similar amounts. Adding hydrogen to the surface shifts the selectivity towards production of ethane as our model predicts. The experimental plot in Figure 4 is curved as it is plotted against $\mathrm{H}_{2}$ exposure which leads to a curved, Langmuir adsorption isotherm-like, dependence of the $\mathrm{H}$ coverage on exposure. The fact that the experimental selectivity slightly favors ethane even when no $\mathrm{H}_{2}$ is deposited suggests that, even when no hydrogen is added onto the surface, a small amount of background hydrogen from the UHV chamber is activated on the surface, as we have observed before. ${ }^{11,42}$

In summary, our theoretical and experimental investigation of the reactivity of ethyl species reveals that PtCu SAAs are bifunctional catalysts, with the dehydrogenation of ethyl occurring on the majority host $\mathrm{Cu}$ sites and the hydrogenation step catalyzed by the minority isolated Pt atom sites. These Pt atoms in the $\mathrm{Cu}(111)$ surface also act as an input channel for hydrogen atoms, the surface coverage of which is shown to control the selectivity of the ethyl disproportionation reaction. These lowtemperature (de)hydrogenation reaction pathways are of general relevance for the heterogeneously catalyzed interconversion of $\mathrm{C}-\mathrm{C}$ and $\mathrm{C}=\mathrm{C}$ bonds and our findings indicate that the selectivity to alkanes vs. alkenes can be tuned by controlling the surface coverage of hydrogen. 


\section{Methods}

Experiments. The surface science experiments were performed in an Omicron low-temperature STM and a separate TPD chamber. Quantitative mass spectrometry was performed on the TPD data to determine the amount of ethylene and ethane evolution. The STM images were acquired at $5 \mathrm{~K}$ (details in SI).

Simulations. The DFT calculations were performed using the optB86b-vdW functional ${ }^{47,48}$ as implemented in VASP 5.4..$^{49-51}$ The surface was modelled with a 4-layer $p(4 \times 4)$ slab. Within the approximations of harmonic Transition State Theory, ${ }^{52,53}$ we evaluated the different rate constants to parameterize, without stiffness-scaling, a graph-theoretical kinetic Monte Carlo model (Zacros 2.0)..$^{54,55}$ In order to decrease the noise resulting from this stochastic approach, we performed each simulation 10 times on a large lattice and averaged the corresponding signals (details in SI).

\section{Supporting Information Available:}

Description of experimental and Computational Methods. Additional data (formation energy of intermediates, functional comparison, additional TPD). Structures of adsorbates and transition states (VASP format) in a separate zip file.

\section{Acknowledgements}

The experimental work at Tufts was supported by the U.S. Department of Energy, by the Division of Chemical Sciences, Office of Basic Energy Science, CPIMS Program, under grant DE-SC 0004738. R. R. is funded by Leverhulme Trust (grant ID: RPG-2018-209). We are also grateful to the UK Materials and Molecular Modelling Hub, which is partially funded by EPSRC (EP/P020194/1), for computational resources. The authors further acknowledge the use of the UCL Myriad High Throughput Computing Facility (Myriad@UCL), and associated support services, in the completion of this work. 


\section{References}

(1) M. T. Darby; M. Stamatakis; A. Michaelides; E. C. H. Sykes. Lonely Atoms with Special Gifts: Breaking Linear Scaling Relationships in Heterogeneous Catalysis with Single-Atom Alloys. J. Phys. Chem. Lett. 2018, 9 (18), 5636-5646.

(2) G. Giannakakis; M. Flytzani-stephanopoulos; E. C. H. Sykes. Single-Atom Alloys as a Reductionist Approach to the Rational Design of Heterogeneous Catalysts. Acc. Chem. Res. 2018, 52, 237-247.

(3) G. Kyriakou; M. B. Boucher; A. D. Jewell; E. a Lewis; T. J. Lawton; A. E. Baber; H. L. Tierney; M. Flytzani-stephanopoulos; E. C. H. Sykes. Isolated Metal Atom Geometries as a Strategy for Selective Heterogeneous Hydrogenations. Science. 2012, 335 (March), 1209-1212.

(4) G. X. Pei; X. Y. Liu; X. Yang; L. Zhang; A. Wang; L. Li; H. Wang; X. Wang; T. Zhang. Performance of Cu-Alloyed Pd Single-Atom Catalyst for Semihydrogenation of Acetylene under Simulated FrontEnd Conditions. ACS Catal. 2017, 7 (2), 1491-1500.

(5) X. Cui; W. Li; P. Ryabchuk; K. Junge; M. Beller. Bridging Homogeneous and Heterogeneous Catalysis by Heterogeneous Single-Metal-Site Catalysts. Nat. Catal. 2018, 1 (6), 385-397.

(6) M. T. Darby; R. Réocreux; E. C. H. Sykes; A. Michaelides; M. Stamatakis. Elucidating the Stability and Reactivity of Surface Intermediates on Single-Atom Alloy Catalysts. ACS Catal. 2018, 8 (6), 5038-5050.

(7) Z.-T. Wang; M. T. Darby; A. J. Therrien; M. El-Soda; A. Michaelides; M. Stamatakis; E. C. H. Sykes. Preparation, Structure, and Surface Chemistry of Ni-Au Single Atom Alloys. J. Phys. Chem. C 2016, 120 (25), 13574-13580.

(8) M. D. Marcinkowski; J. Liu; C. J. Murphy; M. L. Liriano; N. A. Wasio; F. R. Lucci; M. FlytzaniStephanopoulos; E. C. H. Sykes. Selective Formic Acid Dehydrogenation on Pt-Cu Single-Atom Alloys. ACS Catal. 2017, 7 (1), 413-420.

(9) G. X. Pei; X. Y. Liu; A. Wang; A. F. Lee; M. A. Isaacs; L. Li; X. Pan; X. Yang; X. Wang; Z. Tai; et al. Ag Alloyed Pd Single-Atom Catalysts for Efficient Selective Hydrogenation of Acetylene to Ethylene in Excess Ethylene. ACS Catal. 2015, 5 (6), 3717-3725.

(10) A. Wang; J. Li; T. Zhang. Heterogeneous Single-Atom Catalysis. Nat. Rev. Chem. 2018, 2 (6), 6581.

(11) F. R. Lucci; J. Liu; M. D. Marcinkowski; M. Yang; L. F. Allard; M. Flytzani-Stephanopoulos; E. C. H. Sykes. Selective Hydrogenation of 1,3-Butadiene on Platinum-Copper Alloys at the Single-Atom Limit. Nat. Commun. 2015, 6, 8550.

(12) L. Zhang; A. Wang; J. T. Miller; X. Liu; X. Yang; W. Wang; L. Li; Y. Huang; C. Y. Mou; T. Zhang. Efficient and Durable Au Alloyed Pd Single-Atom Catalyst for the Ullmann Reaction of Aryl Chlorides in Water. ACS Catal. 2014, 4 (5), 1546-1553.

(13) R. Réocreux; M. Uhlman; T. Thuening; P. Kress; R. Hannagan; M. Stamatakis; E. C. H. Sykes. Efficient and Selective Carbon-Carbon Coupling on Coke-Resistant PdAu Single-Atom Alloys. Chem. Commun. 2019, 55 (100), 15085-15088. 
(14) F. Zing; J. Jeon; T. Toyao; K. Shimizu; S. Furukawa. Cu-Pd Single-Atom Alloy Catalyst for Highly Efficient NO Reduction. Chem. Sci. 2019.

(15) L. Zhang; H. Liu; S. Liu; M. N. Banis; J. Li; L. Yang; M. Markiewicz; Y. Zhao; R. Li; M. Zheng; et al. Pt / Pd Single Atom Alloys as Highly Active Electrochemical Catalysts and the Origin of Enhanced Activity Pt / Pd Single Atom Alloys as Highly Active Electrochemical Catalysts and the Origin of Enhanced Activity. ACS Catal. 2019.

(16) M.-J. Cheng; E. L. Clark; H. H. Pham; A. T. Bell; M. Head-Gordon. Quantum Mechanical Screening of Single-Atom Bimetallic Alloys for the Selective Reduction of $\mathrm{CO} 2$ to $\mathrm{C} 1 \mathrm{Hydrocarbons.} \mathrm{ACS}$ Catal. 2016, 6 (11), 7769-7777.

(17) Y. Feng; W. An; Z. Wang; Y. Wang; Y. Men; Y. Du. Electrochemical CO2 Reduction Reaction on M@Cu(211) Bimetallic Single-Atom Surface Alloys: Mechanism, Kinetics, and Catalyst Screening. ACS Sustain. Chem. Eng. 2020, 8 (1), 210-222.

(18) G. Sun; Z.-J. Zhao; R. Mu; S. Zha; L. Li; S. Chen; K. Zang; J. Luo; Z. Li; S. C. Purdy; et al. Breaking the Scaling Relationship via Thermally Stable Pt/Cu Single Atom Alloys for Catalytic Dehydrogenation. Nat. Commun. 2018, 9 (1), 4454.

(19) M. D. Marcinkowski; M. Darby; J. Liu; J. Wimble; F. R. Lucci; S. Lee; A. Michaelides; FlytzaniStephanopoulos; M. Stamatakis; E. C. H. Sykes. Pt/Cu Single-Atom Alloys as Coke Resistant Catalysts for Efficient C-H Activation. Nat. Chem. 2018.

(20) R. T. Hannagan; G. Giannakakis; M. Flytzani-stephanopoulos; E. C. H. Sykes. Single-Atom Alloy Catalysis.

(21) M. T. Greiner; T. E. Jones; S. Beeg; L. Zwiener; M. Scherzer; F. Girgsdies; S. Piccinin; M. Armbrüster; A. Knop-Gericke; R. Schlögl. Free-Atom-like d States in Single-Atom Alloy Catalysts. Nat. Chem. 2018, 10 (10), 1008-1015.

(22) A. Khorshidi; J. Violet; J. Hashemi; A. A. Peterson. How Strain Can Break the Scaling Relations of Catalysis. Nat. Catal. 2018, 1 (4), 263-268.

(23) Z. Ma; F. Zaera. Organic Chemistry on Solid Surfaces. Surf. Sci. Rep. 2006, 61 (5), 229-281.

(24) F. Zaera. Direct Observation of Beta-Hydride Elimination Reactions on Metal Surfaces. J. Am. Chem. Soc. 1989, No. 10, 8744-8745.

(25) J. G. Forbes; A. J. Gellman. The Beta-Hydride Elimination Mechanism in Adsorbed Alkyl Groups. J. Am. Chem. Soc. 1993, 115 (14), 6277-6283.

(26) D. Sung; A. J. Gellman. Ethyl lodide Decomposition on $\mathrm{Cu}(111)$ and $\mathrm{Cu}(221)$. Surf. Sci. 2004, 551 (1-2), 59-68.

(27) M. Xi. Evidence for an Eley-Rideal Mechanism in the Addition of Hydrogen Atoms to Unsaturated Hydrocarbons on Cu(111). J. Vac. Sci. Technol. B Microelectron. Nanom. Struct. 1992, 10 (6), 2440.

(28) L. Xu; E. E. Stangland; M. Mavrikakis. Ethylene versus Ethane: A DFT-Based Selectivity Descriptor for Efficient Catalyst Screening. J. Catal. 2018, 362, 18-24. 
(29) H. A. Aleksandrov; L. V Moskaleva; Z.-J. Zhao; D. Basaran; Z.-X. Chen; D. Mei; N. Rösch. Ethylene Conversion to Ethylidyne on $\mathrm{Pd}(111)$ and $\mathrm{Pt}(111)$ : A First-Principles-Based Kinetic Monte Carlo Study. J. Catal. 2012, 285 (1), 187-195.

(30) Y. Chen; D. G. Vlachos. Hydrogenation of Ethylene and Dehydrogenation and Hydrogenolysis of Ethane on Pt(111) and Pt(211): A Density Functional Theory Study. J. Phys. Chem. C 2010, 114 (11), 4973-4982.

(31) Z. J. Zhao; J. P. Greeley. Identification of Surface Intermediates during Ethylidyne Formation on Pt(111) by Calculation of Infrared Intensities and Deuterium Isotope Shifts. Surf. Sci. 2015, 640, 112-118.

(32) F. Zaera; D. Chrysostomou. Propylene on Pt(111) II. Hydrogenation, Dehydrogenation, and H-D Exchange. Surf. Sci. 2000, 457 (1), 89-108.

(33) H. Hoffmann; P. R. Griffiths; F. Zaera. A RAIRS Study on the Surface Chemistry of Ethyl lodide on Pt(111). Surf. Sci. 1992, 262 (1-2), 141-150.

(34) F. Zaera. An Organometallic Guide to the Chemistry of Hydrocarbon Moieties on Transition Metal Surfaces. Chem. Rev. 1995, 95 (8), 2651-2693.

(35) B. E. Bent. Mimicking Aspects of Heterogeneous Catalysis: Generating, Isolating, and Reacting Proposed Surface Intermediates on Single Crystals in Vacuum. Chem. Rev. 1996, 96 (4), 13611390.

(36) F. Zaera. Formation and Thermal Decomposition of Ethyl Groups on Transition Metal Surfaces: Ethyl lodide on Pt(111). Surf. Sci. 1989, 219, 453-466.

(37) T. V. W. Janssens; F. Zaera. Chemistry of Ethylidene Moieties on Platinum Surfaces: 1,1Diiodoethane on Pt(111). J. Phys. Chem. 1996, 100 (33), 14118-14129.

(38) J. Liu; F. R. Lucci; M. Yang; S. Lee; M. D. Marcinkowski; A. J. Therrien; C. T. Williams; E. C. H. Sykes; M. Flytzani-Stephanopoulos. Tackling CO Poisoning with Single-Atom Alloy Catalysts. J. Am. Chem. Soc. 2016, 138 (20), 6396-6399.

(39) M. D. Marcinkowski; M. T. Darby; J. Liu; J. M. Wimble; F. R. Lucci; S. Lee; A. Michaelides; M. Flytzani-Stephanopoulos; M. Stamatakis; E. C. H. Sykes; et al. Pt/Cu Single-Atom Alloys as CokeResistant Catalysts for Efficient C-H Activation. Nat. Chem. 2018, No. January.

(40) M. T. Darby; E. C. H. Sykes; A. Michaelides; M. Stamatakis. Carbon Monoxide Poisoning Resistance and Structural Stability of Single Atom Alloys. Top. Catal. 2018, 61 (5-6), 428-438.

(41) K. G. Papanikolaou; M. T. Darby; M. Stamatakis. Engineering the Surface Architecture of Highly Dilute Alloys: An Ab Initio Monte Carlo Approach. ACS Catal. 2020, 10 (2), 1224-1236.

(42) F. R. Lucci; M. D. Marcinkowski; T. J. Lawton; E. C. H. Sykes. H 2 Activation and Spillover on Catalytically Relevant Pt-Cu Single Atom Alloys. J. Phys. Chem. C 2015, 24351-24357.

(43) K. Yang; B. Yang. Surface Restructuring of Cu-Based Single-Atom Alloy Catalysts under Reaction Conditions: The Essential Role of Adsorbates. Phys. Chem. Chem. Phys. 2017, 19 (27), 1801018017. 
(44) Z.-J. Zhao; L. V. Moskaleva; H. A. Aleksandrov; D. Basaran; N. Rösch. Ethylidyne Formation from Ethylene over Pt(111): A Mechanistic Study from First-Principle Calculations. J. Phys. Chem. C 2010, 114 (28), 12190-12201.

(45) V. I. Avdeev; V. I. Kovalchuk; G. M. Zhidomirov; J. L. D'Itri. Ethylene Adsorption on the Pt-Cu Bimetallic Catalysts. Density Functional Theory Cluster Study. Surf. Sci. 2005, 583 (1), 46-59.

(46) C. J. Jenks; B. E. Bent; F. Zaera. The Chemistry of Alkyl lodides on Copper Surfaces. 2. Influence of Surface Structure on Reactivity. J. Phys. Chem. B 2000, No. 100, 3017-3027.

(47) J. Klimeš; D. R. Bowler; A. Michaelides. Chemical Accuracy for the van Der Waals Density Functional. J. Phys. Condens. Matter 2010, 22, 022201.

(48) J. Klimeš; D. R. Bowler; A. Michaelides. Van Der Waals Density Functionals Applied to Solids. Phys. Rev. B - Condens. Matter Mater. Phys. 2011, 83 (19), 1-13.

(49) G. Kresse; J. Hafner. Ab Initio Molecular Dynamics for Liquid Metals. Phys. Rev. B 1993, 47, 558561.

(50) G. Kresse; J. Furthmüller. Efficiency of Ab-Initio Total Energy Calculations for Metals and Semiconductors Using a Plane-Wave Basis Set. Comput. Mater. Sci. 1996, 6 (1), 15-50.

(51) G. Kresse; J. Furthmüller. Efficient Iterative Schemes for Ab Initio Total-Energy Calculations Using a Plane-Wave Basis Set. Phys. Rev. B 1996, 54, 11169-11186.

(52) M. Stamatakis; D. G. Vlachos. Unraveling the Complexity of Catalytic Reactions via Kinetic Monte Carlo Simulation: Current Status and Frontiers. ACS Catal. 2012, 2 (12), 2648-2663.

(53) R. Réocreux; C. Michel; P. Fleurat-Lessard; P. Sautet; S. N. Steinmann. Evaluating Thermal Corrections for Adsorption Processes at the Metal/Gas Interface. J. Phys. Chem. C 2019, 123 (47), 28828-28835.

(54) M. Stamatakis; D. G. Vlachos. A Graph-Theoretical Kinetic Monte Carlo Framework for on-Lattice Chemical Kinetics. J. Chem. Phys. 2011, 134 (21), 214115.

(55) J. Nielsen; M. D’Avezac; J. Hetherington; M. Stamatakis. Parallel Kinetic Monte Carlo Simulation Framework Incorporating Accurate Models of Adsorbate Lateral Interactions. J. Chem. Phys.

2013, 139 (22), 224706. 